American Journal of Pharmaceutical Education 2020; 84 (8) Article 7909.

\title{
RESEARCH
}

\section{Student Personality Style and First-Year Academic Performance in a Doctor of Pharmacy Program}

\author{
Jon P. Wietholter, PharmD, Lena M. Maynor, PharmD, Jennifer L. Clutter, MA \\ West Virginia University School of Pharmacy, Morgantown, West Virginia \\ Submitted October 30, 2019; accepted December 22, 2019; published August 2020.
}

\begin{abstract}
Objective. To evaluate whether the personality styles of Doctor of Pharmacy (PharmD) students as determined by the DiSC assessment are associated with students' cumulative grade point average (GPA) or with academic penalties imposed in the first year of a PharmD program.

Methods. All incoming PharmD students that provided informed consent and completed the DiSC personality assessment were included in the study. Participants provided demographic data and forwarded their electronic DiSC assessment results to study investigators upon completion. Relevant academic data were collected at the end of each semester.

Results. The overall response rate for the classes of 2019-2022 was 95.6\%. No significant associations were found when comparing personality styles as defined by the DiSC assessment and cumulative GPA at the end of the first year. Additionally, no associations were noted when comparing students' personality style and semester GPA or academic penalties received.

Conclusion. Understanding factors that contribute to students' academic success can aid in early identification of students who are likely to succeed and of students who may benefit from early academic intervention. While no significant associations were found in the first-year of the curriculum, continued evaluation will be conducted to determine the impact of personality style on students' overall academic performance beyond the first year of the PharmD curriculum.
\end{abstract}

Keywords: academic performance, academic success, foundational sciences, personality assessment, personality

\section{INTRODUCTION}

With an increasing percentage of pharmacy students encountering academic difficulty, factors that influence performance are of significant interest. ${ }^{1}$ Several factors have been identified as potential contributors to the academic success of pharmacy students, including grade point average (GPA) in pre-pharmacy coursework, previous achievement of a four-year degree, and critical-thinking skills, while having to repeat one or more pre-pharmacy courses has been shown to be a predictor of academic difficulty. ${ }^{2-9}$ Current literature in higher education suggests that nonperformance-based factors, such as self-efficacy, test anxiety, engagement in co-curricular activities, low levels of academic entitlement, and personality may be associated with academic achievement. ${ }^{4,10-13}$ Multiple methods for characterizing personality have been developed and used to evaluate academic performance. ${ }^{14,15}$ Multiple studies in undergraduate

Corresponding Author: Jon P. Wietholter, West Virginia University, School of Pharmacy, PO Box 9520, Morgantown, WV 26506. Tel: 304-293-1504. Email: jwietholter@hsc.

wvu.edu students use the "Big Five" personality trait framework, which characterizes essential personality traits of agreeableness, conscientiousness, extraversion, neuroticism, and openness. ${ }^{16}$ Data from studies using the Big Five personality traits indicate that high levels of conscientiousness may be associated with better academic performance in undergraduate students, as measured by GPA. ${ }^{10,16-24}$ High levels of conscientiousness, defined by five-factor personality testing, has been shown to be predictive of performance on pre-clinical academic performance and clinical scores on clerkship evaluations in medical students, and the personality descriptor of intuitive-feeling, as defined by Myers Briggs Type Indicator (MBTI) testing, has been associated with lower scores on the National Board of Medical Examiner (NBME) part 1 exam and the Comprehensive Osteopathic Medical Licensing Examination-USA (COMLEX-USA) level 1 exam. ${ }^{15,25,26}$ Furthermore, one longitudinal study has shown that conscientiousness, defined using Big Five personality traits, has increased predictive validity with higher GPA as medical students progress through their training. ${ }^{27}$ While there are data related to personality assessment and academic performance 


\section{American Journal of Pharmaceutical Education 2020; 84 (8) Article 7909.}

in undergraduate and medical students, there is a relative lack of data related to how personality affects academic performance in pharmacy students.

Marston originally proposed his DiSC personality theory in $1928 .^{28}$ The DiSC model has been adapted into a personality assessment tool and is frequently used in the workplace and other environments to describe personalities and focuses on behavioral and interpersonal interactions. The DiSC assessment identifies four personality "styles" as dominance (D), influence (I), steadiness (S), and conscientiousness (C). ${ }^{29}$ The DiSC personality assessment reports are presented as a four-quadrant circle, each representing a personality style. Halves of the circle, ie, left vs right and top vs bottom, are defined as dimensions and broadly describe an individual's external focus and internal pace, respectively. ${ }^{28,29}$ The left half of the circle (dominance and conscientiousness) indicates a task-oriented personality dimension, while the right half (influence and steadiness) reflects a people-orientated personality dimension. The top half (dominance and influence) indicates an outgoing or extraverted personality dimension while the bottom half (conscientiousness and steadiness) indicates a reserved or introverted personality dimension. ${ }^{28,29}$ The authors opted to use the DiSC personality assessment in this study, as the DiSC personality assessment report provides individual users with detailed reports and practical advice for effective interpersonal interactions based on personality styles.

The Doctor of Pharmacy (PharmD) program at the West Virginia University (WVU) School of Pharmacy is a four-year professional degree program. Students may apply to the program after completion of required preadmissions coursework. ${ }^{30}$ The PharmD program includes six didactic semesters, two summer semesters for introductory pharmacy practice experiences (IPPEs) and three semesters (summer, fall, and spring) for advanced pharmacy practice experiences (APPEs). The first year of the didactic curriculum includes courses with a foundational science focus, such as anatomy, physiology, drug delivery, pharmaceutical products, drug chemistry, biopharmaceutics, and biochemical pharmacology, in addition to introductory material related to the practice of pharmacy, including basic pharmacy skills and calculations, and self-care. ${ }^{31}$

The ability to identify specific personality styles associated with academic performance may assist educators in the early identification of PharmD students likely to succeed and those at risk for having academic difficulty. Therefore, the primary objective of this study was to determine the difference in cumulative GPA at the end of the first year of a PharmD program among students with varying personality styles as defined by the DiSC personality assessment. Our hypothesis was that students whose DiSC personality assessment included conscientiousness as the dominant style would have a higher cumulative GPA than other dominant styles. Secondary objectives included comparing personality styles as defined by the DiSC assessment and their impact on GPA each semester, as well as academic penalties imposed. Finally, comparisons of left vs right and top vs bottom dimensions with respect to GPA performance were evaluated as secondary objectives.

\section{METHODS}

This study was part of an ongoing prospective evaluation of DiSC personality styles and academic success based on student cohorts from the classes of 20192022 at the WVU School of Pharmacy. Within this study, multiple aspects of students' academic success were evaluated longitudinally, including GPA and performance in both foundational and clinical courses. The WVU Institutional Review Board approved this project.

During first-year pharmacy student orientation in August of each of the study years (2015-2018), students from the classes of 2019-2022 were provided an overview of the project which included the reasoning behind its development, goals and objectives, and possible risks and benefits of participating. Students were then asked to provide informed consent if they wanted to participate in the study. All incoming students who provided informed consent and completed the DiSC assessment were included in the study. Students were not given any incentive to participate in the study but were informed they would not be charged for the DiSC personality assessment. The school purchased the DiSC assessments through internal grant funds.

Once informed consent was obtained, a link was emailed to each study participant that allowed them to complete the DiSC personality assessment online. Students completed the DiSC personality assessments via an individualized access link at www.thediscpersonalitytest.com and were immediately emailed their results in a PDF format. Participants were instructed to forward their results to the study investigators for evaluation and data collection. Finally, within one week of completing the DiSC assessments, students were offered the opportunity to review their results with someone trained in interpretation of DiSC assessments (this person was neither an investigator nor co-author on the project). These sessions were designed to help students understand what their results meant, how they should interpret and/or use their results, and how their personality style might impact interactions with other personality styles within the PharmD program. 


\section{American Journal of Pharmaceutical Education 2020; 84 (8) Article 7909.}

Demographic data including age, gender, and previous attainment of a bachelor's degree were collected from the school's Office of Admissions and Student Affairs. Academic data were also collected at the end of each academic semester (GPA from each semester, cumulative GPA, and any academic penalties imposed by the school). Grade point average was selected as the primary measure of academic success as it was the cumulative measure used by the PharmD program to determine academic standing and had been used in previous literature. Grade point average was calculated on a 4.0 scale, with an individual course grading scale of $\mathrm{A}=90 \%-100 \% ; \mathrm{B}=80 \%-89.99 \%$; $\mathrm{C}=70 \%-79.99 \%$; and $\mathrm{F}=0-69.99 \%$. Academic probation is imposed when a student fails to receive a grade of at least a $\mathrm{C}$ in one letter-graded course or has a cumulative GPA $<2.5$. A student may be placed on academic suspension if remediation of the academic deficiency requires repetition of a course or rearrangement of the curriculum, such that it is not possible for the student to complete the remediation while continuing to progress through the curriculum. Academic dismissal is imposed if a student is assigned a course grade below $\mathrm{C}$ in two or more courses at any point in the curriculum, if they have a GPA $<1.8$ at the end of the fall semester of the first professional year, or failure to meet terms of academic probation.

GraphPad InStat, version 3.10 (GraphPad Software, San Diego, CA, www.graphpad.com) was used to compare students' personality styles and measures of academic success. We conducted a power calculation for the primary objective, and determined that 32 subjects were needed in each personality domain $(\mathrm{D}, \mathrm{I}, \mathrm{S}, \mathrm{C})$ to have $80 \%$ power to show a difference in GPA of 0.3 . The difference of 0.3 was selected as it represents one-third of a letter grade on a 4.0 scale (ie, the equivalent of a plus or minus letter grade). Mean end-of-semester GPA for both fall and spring semesters and cumulative GPA for the first year were compared via one-way analysis of variance (ANOVA) tests. Association of personality styles and receipt of academic penalties were compared using the chi-square test for independence. Finally, whether students had an undergraduate degree prior to entering the program, female vs male, left vs right (ie, D or C vs I or S), top vs bottom (ie, C or S vs D or I) and conscientiousness vs all other personality styles (C vs D, I, or S) and their impact on mean end-of-semester and cumulative GPAs were evaluated via Mann-Whitney U tests. A significant result was set at a two-sided $\alpha$-level of less than .05 .

\section{RESULTS}

Informed consent forms and DiSC personality assessments were completed by 67 of 79 students from the class of 2019, 70 of 71 students from the class of 2020, 88 of 89 students from the class of 2021, and 79 of 79 students from the class of 2022, for an overall response rate of $95.6 \%$. The most common primary domain from the DiSC assessment in the student cohort was conscientiousness $(C)(n=155)$ followed by steadiness $(S)(n=75)$, influence (I) $(n=63)$, and dominance (D) $(n=34)$. If students had co-primary domains on their DiSC assessment, defined as having the same "score" in each domain, they were counted in both domains (three students were DC/ $\mathrm{CD}$, one student was DI/ID, and 19 students were SC/CS). Demographic data of consenting study participants can be found in Table 1.

With regard to the primary objective to identify any associations between students' personality style and cumulative GPA at the end of their first year, none were found (Table 2). Likewise, no associations were found between personality style and GPAs for the fall and spring semesters. From the perspective of academic penalties, students who were placed on probation, required remediation, withdrew, or were dismissed from the program were considered to have received an academic penalty. Of the four classes included in the study cohort, four students withdrew from the program, three students were dismissed because of academic difficulties, and 22 students were placed on probation and/or required remedial coursework during their first year. A chi-squared test for independence was carried out to evaluate whether academic penalties were more common among students in specific DiSC domains, but no significant differences were noted at the end of the first year in each class $(p=.79)$. Finally, when comparing left vs right ( $\mathrm{D}$ or $\mathrm{C}$ vs I or S), top vs bottom (C or S vs D or I), and conscientiousness vs all other personality styles (C vs D, I, or S) and their impact on end-of-semester and cumulative GPAs, no significant differences were noted (Table 3).

\section{DISCUSSION}

In this cohort of first year pharmacy students, no associations were found between personality style and academic performance defined by cumulative GPA, semester GPA, or academic penalties. With respect to conscientiousness, our findings are somewhat in contrast to work completed in undergraduate and medical students. ${ }^{10,15-27}$ Notably, most work related to personality and academic achievement has been completed using five factor personality model testing. Importantly, conscientiousness, as defined by the DiSC assessment, has been positively associated with conscientiousness, as defined by Big Five assessments. ${ }^{14}$ Additionally, conscientiousness as defined by the NEO-FFI, another five factor model, has been shown to be a predictor of clinical skills in medical students. ${ }^{25}$ The NEO-FFI is a short-form 


\section{American Journal of Pharmaceutical Education 2020; 84 (8) Article 7909.}

Table 1. Demographic Profile of Doctor of Pharmacy Students Included in a Study to Determine Whether There Was an Association Between Students' Personality Traits and Their Performance in the First Professional Year

\begin{tabular}{lcccr}
\hline & $\begin{array}{c}\text { Class of 2019 } \\
(\mathbf{n}=\mathbf{6 7})\end{array}$ & $\begin{array}{c}\text { Class of 2020 } \\
(\mathbf{n}=\mathbf{7 0})\end{array}$ & $\begin{array}{c}\text { Class of 2021 } \\
(\mathbf{n}=\mathbf{8 8})\end{array}$ & $\begin{array}{c}\text { Class of 2022 } \\
(\mathbf{n}=\mathbf{7 9})\end{array}$ \\
\hline Female, No. (\%) & $36(54)$ & $47(67)$ & $48(54)$ & $46(58)$ \\
Mean (SD) age on admission, y & $22.1(4.5)$ & $21.6(1.8)$ & $21.7(2.2)$ & $21.6(2.1)$ \\
Previous four-year degree attained, No. (\%) & $14(21)$ & $23(33)$ & $9(10)$ & $8(10)$ \\
\hline
\end{tabular}

version of the Revised NEO Personality Inventory (NEOPI-R). Similar to the Big Five, the NEO-PI-R has been shown to have a small positive correlation with the conscientiousness DiSC personality. ${ }^{32}$ High levels of conscientiousness are typically associated with an ability to focus on specific tasks, problem-focused coping, goal making, rule compliance, and self-regulation, all of which may be desirable behaviors with regard to academic performance. ${ }^{10,25}$

Conscientiousness in the context of the DiSC assessment can be described as task and detail-oriented, wants all information, and slower moving. ${ }^{28}$ The DiSC assessment is designed such that there is an approximately even distribution of personality styles among the general population. ${ }^{33}$ Nearly half $(47 \%)$ of our cohort displayed conscientiousness as their dominant style, while only $10 \%$ of our cohort displayed dominance as their dominant style. In addition, the overall average GPA of our incoming first year students is $3.5 .^{34}$ This may indicate a benefit of conscientiousness (or behaviors associated with conscientiousness) and academic success in pre-pharmacy courses and admission to the program, while not currently translating into a predictor of academic success within the first year of our PharmD program.

In studies prior to transition to the PharmD as the entry-level pharmacy degree in the United States, math/ science pre-pharmacy GPA, achievement of a four-year degree prior to entering pharmacy school, and criticalthinking skills were identified as predictors of success in first-year pharmacy students. ${ }^{2,3,6}$ More recent work has focused on other non-performance-based factors that play a role in academic achievement. Higher perceived selfefficacy, better achievement calibration (the discrepancy between a student's expectation of his or her own performance and actual course grade), test competence (the ability to cope with the amount of study material for an examination), and academic competence (the ability to manage one's study load) have been found to be associated with higher academic performance in pharmacy students. ${ }^{4,5}$ Additionally, types of achievement goal setting, emotional intelligence, and most recently, grit, have been suggested as possible contributing factors to academic performance in pharmacy students. ${ }^{35-39} \mathrm{~A}$ determination of how personality affects academic performance is useful in the context of these varied nonperformance-based factors.

While no distinct differences were noted for the first year of our PharmD curriculum, data collection on performance in other years of the pharmacy curriculum, including in experiential courses, is ongoing. Given existing data in medical students, it is possible differences in academic performance based on personality domains will be found in more clinically-focused didactic courses, as well as experiential courses, even though no differences were found in the first academic year. If differences in academic performance based on personality for later parts of the curriculum can be identified, this could impact pharmacy education in that it may result in incorporation of personality assessments early in the curriculum to assist in identification of students who may need additional support. Depending on findings, the feasibility of working with other health sciences professions (eg, medicine,

Table 2. Primary Personality Domains Examined in a Study to Determine Whether There is an Association Between Students' Personality Traits and Their Academic Performance ${ }^{\mathrm{a}}$

\begin{tabular}{|c|c|c|c|c|c|}
\hline Mean GPA ${ }^{b}$ & Dominance $n=34$ & Influence $n=63$ & Steadiness $n=75$ & Conscientiousness $n=155$ & $p$ value \\
\hline Fall semester GPA & $3.28(0.52)$ & $3.27(0.59)$ & $3.29(0.66)$ & $3.39(0.61)$ & .46 \\
\hline Spring semester GPA & $3.60(0.38)$ & $3.56(0.44)$ & $3.51(0.55)$ & $3.63(0.39)$ & .23 \\
\hline Cumulative first-year GPA & $3.44(0.42)$ & $3.40(0.49)$ & $3.39(0.56)$ & $3.50(0.50)$ & .42 \\
\hline
\end{tabular}

Abbreviation: GPA= grade point average

a If students had co-primary domains on their DiSC assessment, they were counted in both domains; three students were DC/CD; one student was $\mathrm{DI} / \mathrm{ID} ; 19$ students were SC/CS

${ }^{\mathrm{b}} \mathrm{A}=4.0, \mathrm{~B}=3.0, \mathrm{C}=2.0, \mathrm{~F}=0.0$ 


\section{American Journal of Pharmaceutical Education 2020; 84 (8) Article 7909.}

Table 3. Personality Dimensions Examined in a Study to Determine Whether There is an Association Between Students' Personality Traits and Their Academic Performance

\begin{tabular}{lccc}
\hline & Mean GPA (SD) & Median GPA & $p$ value \\
\hline Left vs right dimension & DC: $3.48(0.49)$ & DC: 3.62 & .17 \\
DC $(\mathrm{n}=186)$ vs IS $(\mathrm{n}=138)^{\mathrm{a}}$ & IS: $3.40(0.53)$ & IS: 3.48 & .26 \\
Top vs bottom dimension & CS: $3.46(0.53)$ & CS: 3.61 & .08 \\
CS $(\mathrm{n}=211)$ vs DI $(\mathrm{n}=96)^{\mathrm{b}}$ & DI: $3.42(0.47)$ & DI: 3.46 & C: 3.66 \\
Conscientiousness vs all other domains & C: $3.50(0.50)$ & DIS: 3.47 & \\
C $(\mathrm{n}=155)$ vs DIS $(\mathrm{n}=171)^{\mathrm{c}}$ & DIS: $3.41(0.51)$ &
\end{tabular}

Abbreviations: $\mathrm{D}=$ dominance; $\mathrm{I}=$ influence; $\mathrm{S}=$ steadiness; $\mathrm{C}=$ conscientiousness; $\mathrm{GPA}=$ grade point average

${ }^{\text {a }}$ Students with co-dominant SC/CS $(\mathrm{n}=19)$ or DI/ID $(\mathrm{n}=1)$ domains were excluded from this analysis

${ }^{\mathrm{b}}$ Students with co-dominant $\mathrm{DC} / \mathrm{CD}(\mathrm{n}=3)$ domains were excluded from this analysis

${ }^{c}$ Students with co-dominant SC/CS $(n=19)$ or $\mathrm{DC} / \mathrm{CD}(\mathrm{n}=3)$ domains were excluded from this analysis

nursing, dentistry) to carry out a similar study within their disciplines should also be considered.

Limitations of our study include containing data from a single PharmD program. Additionally, our study focused on personality as a predictor of academic success, primarily defined by GPA, and does not account for other factors that may contribute to academic success, including those from outside the classroom (eg, work situations, financial stress, mental health, or other health issues). Students participating in our study completed the DiSC assessment during P1 orientation, prior to the start of classes within the PharmD program. Some published work related to medical students has theorized that certain personality traits manifest as they are needed for academic success as described by trait-activation theory. ${ }^{15}$ If this is the case, certain aspects of the DiSC personality style may have varied if we had given the assessment later in the semester once classes were underway. Finally, there were a significant number of students with a 4.0 GPA within this cohort; this likely limits the ability to discriminate among individual performance and could potentially skew results.

\section{CONCLUSION}

In conclusion, while no significant differences were found in first-year performance based on DiSC personality styles, this information still provides an important contribution in the search for nonperformance-based factors on achievement in pharmacy students. A full understanding of the complex factors that contribute to student success is necessary for PharmD programs to ensure admission of students who are likely to succeed and to aid in early identification of students who may benefit from academic intervention.

\section{ACKNOWLEDGMENTS}

The authors would like to acknowledge Dr. Justin Hare for providing students insight into what their results mean regarding personality style and how they may best interact with others, and the West Virginia University School of Pharmacy Clinical Department for providing grant support through the Arthur I. Jacknowitz Distinguished Chair Funds.

\section{REFERENCES}

1. Maize DF, Fuller SH, Hritcko PM, et al. A review of remediation programs in pharmacy and other health professions. Am J Pharm Educ. 2010;74(2):25

2. Chisholm MA, Cobb HH, Kotzan JA. Significant factors for predicting academic success of first-year pharmacy students. Am J Pharm Educ. 1995;59:364-370.

3. Chisholm MA, Cobb HH, Kotzan JA, Lautenschlager G. Prior four year college degree and academic performance of first year pharmacy students: a three year study. Am J Pharm Educ. 1997; 61:278-281.

4. Carroll CA, Garavalia LS. Factors contributing to the academic achievement of pharmacy students: use of the goal-efficacy framework. Am J Pharm Educ. 2004;68(4):88.

5. Sansgiry SS, Bhosle M, Sail K. Factors that affect academic performance among pharmacy students. Am J Pharm Educ. 2006; 70(5): 104 .

6. Comer RD, Schweiger TA, Shelton P. Impact of students' strengths, critical thinking skills and disposition on academic success in the first year of a PharmD program. Am J Pharm Educ. 2019; 83(1):6499.

7. Steinberg M, Morin AK. The impact of prematriculation admission characteristics on graduation rates in an accelerated doctor of pharmacy program. Am J Pharm Educ. 2015;79(8):118.

8. Tejada FR, Parmar JR, Purnell M, Lang LA. Admissions criteria as predictors of academic performance in a three-year pharmacy program. Am J Pharm Educ. 2016;80(1):6.

9. Hansen DJ, Mort JR, Brandenburger T, Lempola A. Relationship of prepharmacy repeat course history to students' early academic difficulty in a pharmacy curriculum. Am J Pharm Educ. 2015;79(10):154.

10. Poropat AE. Other-rated personality and academic performance: Evidence and implications. Learn Individ Differ. 2014;34:24-32.

11. Fox LM, Sease JM. Impact of co-curricular involvement on academic success of pharmacy students. Curr Pharm Teach Learn. 2019;11(5):461-468. 


\section{American Journal of Pharmaceutical Education 2020; 84 (8) Article 7909.}

12. Jeffres MN, Barclay SM, Stolte SK. Academic entitlement and academic performance in graduating pharmacy students. Am J Pharm Educ. 2014;78(6): 116.

13. Ubaka CM, Sansgiry SS, Ukwe C V. Cognitive determinants of academic performance in Nigerian pharmacy schools. Am J Pharm Educ. 2015;79(7):101.

14. Jones CS, Hartley NT. Comparing correlations between fourquadrant and five-factor personality assessments. Am J Bus Educ. 2013;6(4):459-470.

15. Hojat M, Erdmann JB, Gonnella JS. Personality assessments and outcomes in medical education and the practice of medicine: AMEE Guide No. 79. Med Teach. 2013;35:e1267-e1301.

16. Komarraju M, Karau SJ, Schmeck RR. Role of the Big Five personality traits in predicting college students' academic motivation and achievement. Learn Individ Differ. 2009;19:47-52.

17. Vedel A, Thomsen DK, Larsen L. Personality, academic majors and performance: revealing complex patterns. Pers Individ Dif. 2015;85:69-76.

18. Cheng W, Ickes W. Conscientiousness and self-motivation as mutually compensatory predictors of university-level GPA. Pers Individ Dif. 2009;49:817-822.

19. Vedel A. The Big Five and tertiary academic performance: a systematic review and meta-analysis. Pers Individ Dif. 2014;71: 66-76.

20. Vianello M, Robusto E, Anselmi P. Implicit conscientiousness predicts academic performance. Pers Individ Dif. 2010;48:452-457. 21. Marcela V. Learning strategy, personality traits and academic achievement of university students. Procedia - Soc Behav Sci. 2015;174:3473-3478.

22. Hakimi S, Hejazi E, Lavasani MG. The relationships between personality traits and students' academic achievement. Procedia Soc Behav Sci. 2011;29:836-845.

23. Hazrati-Viari A, Rad AT, Torabi SS. The effect of personality traits on academic performance: the mediating role of academic motivation. Procedia - Soc Behav Sci. 2012;32:367-371.

24. Ciorbea I, Pasarica F. The student of the relationship between personality and academic performance. Procedia - Soc Behav Sci. 2013;78:400-404.

25. Haight SJ, Chibnall JT, Schindler DL, Slavin SJ. Associations of medical student personality and health/wellness characteristics with their medical school performance across the curriculum. Acad Med. 2012;87(4):476-485.

26. Doherty EM, Nugent E. Personality factors and medical training: A review of the literature. Med Educ. 2011;45(2):132-140.
27. Lievens F, Ones DS, Dilchert S. Personality scale validities increase throughout medical school. J Appl Psychol. 2009;94(6): 1514-1535.

28. Rohm RA. A powerful way to understand people using the DISC personality concept. https://www.personality-insights.com/what-isdisc-personality/. Accessed July 23, 2020.

29. Everything DiSC. About Everything DiSC: Theory and Research. https://www.everythingdisc.com/EverythingDiSC/media/ SiteFiles/Assets/History/Everything-DiSC-resources-aboutdisc.pdf. Accessed July 23, 2020.

30. West Viginia University School of Pharmacy. Pharm.D. program. https://pharmacy.hsc.wvu.edu/student-services/pharmdprogram/. Accessed July 23, 2020.

31. West Virginia University School of Pharmacy. Pharmacy curriculum. https://pharmacy.hsc.wvu.edu/student-services/pharmdprogram/pharmacy-curriculum/. Accessed July 23, 2020.

32. EverythingDiSC. Research report of adaptive testing assessment. https://www.everythingdisc.com/EverythingDiSC/media/SiteFiles/ Assets/History/Everything-DiSC-Research-Report.pdf. Published 2013. Accessed July 23, 2020.

33. EverythingDiSC. Frequently asked questions about DiSC. https://www.discprofile.com/what-is-disc/faq/. Accessed July 23, 2020.

34. West Virginia University School of Pharmacy. Top ten questions. https://pharmacy.hsc.wvu.edu/student-services/prepharmacy/top-ten-questions/. Accessed July 23, 2020.

35. Alrakaf S, Anderson C, Coulman SA, et al. An international comparison study of pharmacy students' achievement goals and their relationship to assessment type and scores. Am J Pharm Educ. 2015;79(3):35.

36. Hall M, Hanna L, Hanna A, Hall K. Associations between achievement goal orientations and academic performance among students at a UK pharmacy school. Am J Pharm Educ. 2015;79(5):64. 37. Romanelli F, Cain J, Smith KM. Emotional intelligence as a predictor of academic and/or professional success. Am J Pharm Educ. 2006;70(3):69.

38. Palisoc AJL, Matsumoto RR, Ho J, Perry PJ, Tang TT, Ip EJ. Relationship between grit with academic performance and attainment of postgraduate training in pharmacy students. Am J Pharm Educ. 2017;81(4):67.

39. Pate AN, Payakachat N, Harrell TK, Pate KA, Caldwell DJ, Franks AM. Measurement of grit and correlation to student pharmacist academic performance. Am J Pharm Educ. 2017;81(6):105. 